\title{
Eficácia de um programa de promoção da saúde em infantes de pré-escola na cidade de Anápolis, Goiás
}

\author{
Effectiveness of a health promotion \\ in pre-school infants program in the city of Anápolis, Goiás State
}

Thaís Bueno $\mathrm{M}$ achado deOliveira ${ }^{1}$

Lúcia H elena Presoto ${ }^{2}$

\footnotetext{
${ }^{1}$ Departamento deM edicina Preventiva, Escola Paulista deM edicina, Universidade Federal deSão Paulo. Rua Borges Lagoa 1341/20 andar, VilaClementino. 04038-034 São Paulo SP. thaisbuenomom@hotmail.com ${ }^{2}$ FaculdadedeSaúde Pública, Universidade de São Paulo.
}

\begin{abstract}
This work aimed to analyze the assistance given by a health promotion in pre-school infants program in the city of Anápolis, Goiás State, as well as the forms of participation of the ones involved. Thus, statistical attendance dates were collected, as well as the realization of interviews with the respective parents and/or responsible for the infants, and also theones, showing a sample of 119 and 19 people, respectively. Analyzing the collected data, it can be concluded that the effectiveness of the program, considering the perceptions of the interviewed ones, is showed as satisfactory on its global aspect. Key words $\mathrm{H}$ ealth promotion, Education in health, Program, Infant
\end{abstract}

Resumo Este trabalho objetivou analisar a assistência prestada por um programa de promoção da saúdeem infantes de pré escola na cidadedeAnápolis, Goiás, bem como as formas de participação dos seus envolvidos. Para tanto, foram levantados dados estatísticos de atendimentos, bem como a realização de entrevistas com os respectivos pais e/ ou responsáveis por esses infantes ( 119 entrevistados), como também com os responsáveis pela sua execução (19 entrevistados). Pelos dados obtidos, pode-se concluir que a eficácia do programa, considerando-se as percepções acerca do mesmo, pel os entrevistados, sinaliza como sati sfatória em seu aspecto global.

Palavras-chave Promoção da saúde, Educação em saúde, Programa, Infante 
Introdução

N os anos cinquenta, surgiu no Brasil, pela ação do educador Paulo Freire', reflexões sobre os movimentos sociais e o processo de educação participativa e emancipatória, pelas quais as pessoas são atores na e da história, capazes de identificar problemas e formular soluções, transformando-se e modificando conceitos opressores. Elege-se como princípio básico da educação a liberdade humana, cujo significado é o de que as pessoas passam a ser sujeitos de seu próprio aprendizado e, por meio de uma abordagem dialógica, todos possam participar como co-aprendizes, criando uma realidade de compreensão conjunta, envolvendo todos na identificação de seus problemas.

A partir da década de setenta, no Brasil, a área de educação em saúde vem propondo uma linha de planejamento participativo para as ações educativas, fazendo-o com base na pedagogia da problematização, criando uma nova concepção de educação em saúde, voltada para um processo positivo de educar, cujo objetivo é valorizar a responsabilidade sobre a saúde pessoal, da família e da comunidade? 2 .

Respondendo à realidade social desta década, a educação em saúde opta por deixar de lado 0 caráter autoritário até então adotado e passa a reconhecer a importância da participação popular e seu direito de conduzir o próprio destino quanto à saúde. N essesentido, passa a preocupar-se em instrumentalizar as pessoas, grupos e comunidades na conquista da sua cidadania, da qual a saúde é apenas uma parcela?.

A opção pela população enão pelo poder constituído foi um passo decisivo na história da educação em saúde, pois, a partir deste momento, ela coloca todo o seu patrimônio à disposição das pessoas e passa a construir sua prática em parceria com essa, de forma a atender seus anseios e necessidades.

Inserida nessa temática, a construção da saúde, enquanto valor, está relacionada à conquista dos direitos sociais, às condições dignas de vida, trabalho, moradia e ao acesso aos serviços de saúde de boa qualidade, sendo que, a saúde, enquanto necessidade, searticula diretamentecom a ampliação da cidadania política e social, visto que a ampliação quantitativa e qualitativa dos serviços de assistência à saúde constituem um direito elementar à cidadania. Sabe-se que os cidadãos brasileiros, na sua maioria, não conseguiram ainda ser cidadãos de corpo inteiro, pois, embora as políticas de saúde explicitem as diretrizes deação ebases operacionais para a universalidade e equidade de acesso a mesma, na prática existem distorções que refletem na qualidade de vida destas pessoas.

Todavia, ao longo das últimas décadas, têm crescido significativamente as pesquisas abordando esta temática, demonstrando a importância da compreensão deste objeto de estudo a partir da ótica biopsicossocial. Este último aspecto mostrase importante para a nossa pesquisa, cujo interesse central é analisar a assistência prestada por um programa de promoção da saúde para infantes do Serviço Social do Comércio (SESC), na cidade de Anápolis, Goiás, bem como as formas de participação dos seus envolvidos, estudando sua estrutura, composição, organização e atuação no contexto proposto. Sendo o tema de grande complexidade, torna-se necessário o desenvolvimento de mais estudos e atual ização constante dos diferentes profissionais que atuam com promoção da saúde; como agentes modificadores desse processo, justifica-se a relevância deste estudo.

Esse artigo apresenta a abordagem dividida em duas partes, sendo que, na primeira, apresentaremos considerações e evolução do programa, bem como um levantamento dos registros históricos, suas abordagens e limitações, e a apresentação da pesquisa de campo.

Faz-se imprescindível ao sucesso de um programa como o aqui apresentado a mensuração do mesmo. Para tanto, é necessário observarmos seus resultados com relação à sua eficiência, mensurando como o trabalho é realizado no seu processo de desenvolvimento; sua eficácia, verificando se os resultados obtidos se aproximam dos almejados e, por fim, sua efetividade, observando se 0 custo/benefício do mesmo foi satisfatório, sendo imperioso o esclarecimento de que o referido programa é desenvolvido sem ônus aos participantes.

N este estudo, nos apegamos aos resultados com base em sua eficiência e eficácia, usando para tal questionários aplicados aos envolvidos na execução do programa e entrevistas feitas com os pais/responsáveis pelos infantes envolvidos no programa.

\section{O programa de promoção da saúde parainfantes do SESC Goiás: Projeto AM ONS}

\section{Origem e evolução}

Alicerçado na missão do SESC de "contribuir para o bem-estar e melhoria da qualidade de vida e desenvolvimento cultural dos comerciários edesua família, priorizando a ação educativa, permanente e propositiva em todas as suas realizações" ${ }^{4}$, no ano de 1990, instituiu-se a primeira edição de um 
programa de promoção da saúde denominado Projeto AM ONS, cuja sigla significa acompanhamento médico, odontológico, nutricional e social.

Este projeto é desenvolvido, desde a sua primeira edição, por uma equipe multiprofissional, em parceria com as atividades das áreas de saúde, educação e assistência social da instituição, sendo que a essência do mesmo se mantém ao longo dos anos, modificando apenas algumas condutas de ação para melhor se adequar às inovações conceituais surgidas ao longo dos anos.

\section{Objetivos do projeto}

O escopo do projeto está fundamentado nos princípios da promoção da saúde, usando a educação para a saúde como instrumento para aplicá-lo.

Dentre os seus objetivos, destacam-se a contribuição para a melhoria da qualidade de vida dos alunos da préescola efamília a partir do fortalecimento de hábitos saudáveis nos aspectos pedagógico, médico, odontológico, nutricional e social.

U sa-se parara contemplá-los a busca pelo comprometimento dos familiares nas reuniões promovidas pelos executores da assistência social; o estabelecimento de estratégias de orientação e viabilização de acesso aos alunos e familiares nas ações desenvolvidas a partir de diagnósticos apresentados pelos multiprofissionais envolvidos; contribuição para o desenvolvimento e preservação da saúde desses infantes através de ações pedagógicas do cotidiano escolar, assim como a realização deações educativas e de intervenções que possam contribuir para a manutenção de ambientes saudáveis para 0 aprendizado.

M etodologia de ação

e operacionalização do projeto

As ações acontecem na esfera da promoção e proteção à saúde, buscando um fortalecimento de hábitos, reforçando o exercício da cidadania (direito à saúde) na instância familiar, uma vez que os infantes são considerados agentes multiplicadores em saúde dentro do contexto do projeto.

Para a instrumentalização desses infantes, são utilizadas as bases pedagógicas da construção do saber, colocando-os como agentes ativos nesta construção.

Acompanhamento pedagógico

Cerca-se de um papel fundamental para, através de atividades pedagógicas, dar continuidade às ações promovidas pelas demais áreas envolvidas no projeto, no sentido de reforçar hábitos saudáveis dos infantes, fazendo o acompanhamento diário eparticipando do encaminhamento dessesaos serviços médico, odontológico, nutricional esocial quando se fizer necessário.

\section{Acompanhamento médico}

Objetiva-se com o acompanhamento anual do infantea preven ção das principais doenças da primeira infância, orientando e esclarecendo os familiares acerca das enfermidades de maior incidência, assim como a importância do controle do cartão de vacina.

Acompanhamento odontológico

Segundo Pinto ${ }^{5}$, a cárie dentária e a doença periodontal (de gengiva) são problemas de saúde bucal comuns em todo o mundo; ocorrem entre $50 \%$ e $99 \%$ das pessoas na maioria das comunidades. Para medir a incidência dessas doenças, foi criado um método de avaliação que é aceito por toda a comunidade internacional como indicador do perfil da saúde bucal, denominado DMFT em inglês ou CPO-D em português. Essa sigla é uma representação numérica que indica a prevalência de cárie dental no indivíduo (ou em uma determinada população estudada) eécal culada a partir da quantidadededentes cariados $(C)$, dentes perdidos $(P)$ e dentes obturados $(0)$, sendo que a terminologia compatível a esse usada na dentição temporária é ceo-d (dentes cariados, extraídos eobturados), tendo sido o método de eleição para a realização do diagnóstico das condições bucais no projeto.

Seguindo as normas de calibração desenvolvidas pelo M inistério da Saúde, apenas uma cirurgiã-dentista é a responsável pelo exame, assegurando, assim, a uniformidade de interpretação, compreensão e aplicação dos critérios para as várias doenças, padronizando o objeto daquilo que se está analisando, no caso, a cárie.

Também são utilizadososISG (índice desangramento gengival) eIPV (índicede placa visível) para mensurar as condições de higiene bucal, hierarquizando os problemas e definindo as prioridades.

0 atendimento clínico se dá pela atenção odontológica básica de saúde, com prevenção, profilaxias dentárias, restaurações, extrações, cuidados de urgências, etc., além, da realização da escovação supervisionada junto aos infantes na escola, bem como a realização de capacitações com os professores, a fim de que estes façam um melhor acompanhamento da escovação dos infantes e orientações aos pais com relação à importância da prevenção e promoção de saúde bucal. 
Acompanhamento nutricional

Tal acompanhamento dá-se em três etapas:

1) Coletas de medidas antropométricas - me dem-se as variáveisfísicas e a composição nutricional do corpo humano, coletando-se o peso e a altura de todos os infantes, usando índices peso/ altura, altura/idade e peso/idade. Após a obtenção dos dados, os que apresentam desvio do estado nutricional são convidados, juntamente com seu responsável, a fazer 0 acompanhamento dietote rápico com o objetivo de contribuir para a melhoria do estado nutricional do mesmo.

2) Exame - constituído de avaliação nutricional, definição do percentil, anamnese alimentar, determinação da conduta dietoterápica, com orientações aos pais e/ou responsáveis sobre o resultado do diagnóstico do infante e agendamento do retorno para os que necessitam de tratamento.

3) Tratamento - consiste em revisão das orientações nutricionais, revisão da anamnese alimentar, avaliação da adesão do infante e do responsável ao tratamento proposto, através da verificação de redução ou aumento de peso e alterações nos hábitos alimentares ecoleta de peso para acompanhamento.

\section{Acompanhamento social}

Ocorre durante todo o processo de desenvolvimento do projeto, a partir da concepção da interdisciplinaridade. Para tanto, desenvolve-se uma leitura inter-relacional dos dados obtidos pelas demais áreas, cujas situações mereçam a construção do saber e o fortalecimento de hábitos e comportamentos em família. Partilha-se, assim, com as famílias, professores, equipe e infantes; orientase sobre os mais diversos temas, considerando a globalidade do indivíduo no sentido do entendimento er eflexão quanto ao exercício da cidadania, tendo em vista o processo de promoção e prote ção à saúde, instrumentalizando teoricamente 0 trinômio família/infante/professores como agentes multiplicadores de informações junto ao seu meio social.

Pesquisa de campo

Proposição

Entrevistas com pais e/ou responsáveis

Para a análise qualitativa do Projeto AM ONS através da opinião dos pais e/ou responsáveis pelos infantes envolvidos, optamos pelo uso de um questionário como instrumento de coleta de dados, considerando-se as seguintes variáveis:

1. O rientações recebidas quanto à execução do projeto;

2. Acompanhamento médico;
3. Acompanhamento odontológico;

4. Acompanhamento nutricional;

5. Acompanhamento pedagógico;

6. Participação em encontros voltados para 0 acompanhamento e orientações sociais;

7. Relevância dos temas, assim como as formas de abordagens durantes as pal estras do acompanhamento social;

8. Aquisição de novos conhecimentos;

9. Aquisição de novos hábitos e/ou condutas; e 10. N ota atribuída ao projeto.

Entrevista com os responsáveis pela execução do projeto

Nesta fase, optamos pela técnica da entrevista semi-estruturada, cujo roteiro segue as variáveis demonstradas abaixo, tendo como objetivo traçar o grau de envolvimento e opinião desses:

1. Critérios utilizados para observar as necessidades das crianças em seu contexto social;

2. Grau de envolvimento com o projeto;

3. Participação de reciclagens e/ou treinamentos voltados para o Projeto AM ONS;

4. A preciação sobre os treinamentos e/ou reciclagens;

5. Q ualidade e abrangência dos serviços prestados;

6. A preciação sobre a abordagem social feita através das palestras; e

7. Observação de mudanças de hábitos e/ou comportamentos nos infantes e/ou familiares.

\section{M aterial e método}

Para desenvolver este trabalho, cujo campo de estudo foi o Serviço Social do Comércio (SESC) da cidade de Anápolis, Goiás, optamos pela metodologia quali-quantitativa, justificando a opção desta escolha utilizando, para tanto, o conceito de $\mathrm{M} \mathrm{i-}$ nayo ${ }^{6}$, que assim caracteriza pesquisa qualitativa: [...] como aquela capaz de incorporar a questão do significado e da intencionalidade como inerentes aos atores, às relações eàs estruturas sociais, não se preocupando em quantificar, mas em explicar os meandros das relações sociais consideradas essência e resultado da atividade humana criadora, afetiva e racional podendo ser aprendidas através do cotidiano $0^{6}$.

Elegendo o estudo de caso como método de nosso estudo, por objetivar, segundo Becker ${ }^{7}$, compreender todo o comportamento do grupo estudado, não podendo ser concebido segundo uma mentalidade única para testar proposições gerais, tendo de ser preparado para lidar com uma grande variedade de problemas teóricos e descritivos. 
0 estudo de caso geralmente tem duplo propósito: [...] por um lado tenta chegar a uma compreensão abrangente do grupo em estudo: quem são seus membros? Quais são suas modalidades de atividadee interação recorrentes e estáveis? Como elas se relacionam umas com as outras e como o grupo está relacionado com o resto do mundo? Ao mesmo tempo, 0 estudo de caso também tenta desenvolver declarações teóricas mais gerais sobre regularidades do processo e estruturas sociais, sendo que, os vários fenômenos revelados pelas observações do investigador têm que ser todos incorporados ao seu relato do grupo e em seguida receber atribuiç̧ões de relevância teórica ${ }^{7}$.

0 estudo de caso prepara o investigador para lidar com descobertas inesperadas e, de fato, exige que ele reoriente seu estudo à luz de tais desenvolvimentos. Força-o a considerar, por mais que de modo rudimentar, as múltiplas inter-relações dos fenômenos específicos que observa?.

Os objetivos do estudo de caso e os tipos de problemas que geralmente coloca sugerem técnicas específicas de coleta de dados, sen do eleitas para este estudo a técnica de observação participante, com o engajamento em diferentes tarefas: registro completo dos eventos observados em diário de campo, entrevistas e pesquisa documental.

A análise dos dados coletados foi sequencial, isto é, realizada paralelamente à execução do estudo, em que, segundo Becker ${ }^{7}$, os resultados de análises anteriores podem ser usados para dirigir outras operações de coletas de dados, inserindo problemas que surgem nos diferentes estágios da pesquisa e promovendo um refinamento progressivo do mesmo.

$\mathrm{Na}$ análise quantitativa, o que serve de informação é a frequência de certas características do conteúdo. Objetividade não pode ser confundida com cientificidade, sendo perfeitamente possível combinar compreensão dos fatos com estatística ${ }^{8}$. Por se entender perfeitamente a referida combinação e tendo em vista que a mesma propiciaria meIhor compreensão dos aspectos objetivos e subjetivos da realidade em estudo, é que adotamos esta combinação metodológica.

Como sujeitos de pesquisa, foram selecionados os 119 infantes matriculados na pré-escola e seus pais e/ou responsáveis, bem como os envolvidos na execução do Projeto AM ONS, executado pelo Serviço Social do Comércio (SESC) do município de Anápolis, Goiás.

Primamos por respeitar a liberdade individual destas pessoas no concernente à participação na pesquisa tendo, os que anuíram, assinado um termo de consentimento livre e esclarecido.

Sobreleva que nenhuma entrevista ou questio- nário foi desprezado, por mais inexpressivas que parecessem suas respostas, por ser exatamente esta a intenção da pesquisa: verificar o grau de informação e envolvimento da população em questão.

\section{Observação participante}

\section{Apresentando os dados da assistência} do Projeto AMONS

A parte concernente à assistência pedagógica do projeto se fez presente, favorecendo assim o intercâmbio entre família/escola. No âmbito das salas de aula, trabalhou-se com as crianças conteúdos que favorecem o desenvolvimento e pre servação da saúde (hábitos higiênicos para a alimentação, higiene pessoal, higieneambiental), além da realização de atividades que auxiliam na formação de hábitos salutares a esses infantes, tais como lavagem das mãos, higienização da cavidade bucal, lavagem dos alimentos antes da preparação e a construção de murais/painéis com pesquisas realizadas pelas crianças sobre os temas que abrangem o Projeto AMONS, primando por favorecer os infantes com ambientes favoráveis ao aprendizado durante 0 transcorrer do ano letivo.

0 acompanhamento médico se deu primeiramente com a distribuição das fichas de avaliação médica, a serem preenchidas pelos pais, para a coleta de dados relevantes para o inventário da saúde do infante. Após o preenchimento destas, realizou-se o exame físico individual, além da coleta das medidas antropométricas, realizadas por uma estagiária de nutrição integrante do quadro funcional da instituição.

A pós a compilação dos dados, foi possível observar que os alunos, em sua maioria, apresentavam-sehígidosno dia da avaliação. Obteve-se, também, o diagnóstico presuntivo de molusco contagioso em um infante; uma linfoadenomegalia a esclarecer, além decasos degripee um caso isolado de crise de bronquite. Os outros diagnósticos já estavam estabelecidos.

A assistência odontológica realizou primeiramente o levantamento epidemiológico das crianças para aferir as necessidades bucais das mesmas, além do mapeamento com índice de placa visível e índice de sangramento gengival.

Procedeu-se com a capacitação das professoras da educação infantil e apresentação dos resultados do levantamento epidemiológico às mesmas.

Em seguida, tiveram prosseguimento as ações preconizadas, apresentando-se o projeto aos pais, nas quais todas as atividades envolvidas expuse ram suas ações, dentre elas a assistência odontológica, que abordou a forma como este seria execu- 
tado durante 0 ano letivo, tanto com os infantes quanto com os familiares e professores. Efetivando-se, no que se refere às crianças:

- I dentificação das necessidades epidemiológicas e realização do diagnóstico;

. Hierarquização dos problemas e definição de prioridades;

- Atenção odontológica básica de saúde bucal;

- Implantação, controle e avaliação do flúor na escola; e

. Controledo índice desangramento gengival e deplaca visível.

No que toca aos professores:

- Capacitação a fim defazer o acompanhamento da saúde bucal e escovação supervisionada das crianças;

No que diz respeito aos familiares:

- Orientações quanto à importância da prevenção e promoção da saúde bucal, repassandose aos pais e/ou responsáveis presentes os conceitos básicos sobre saúde bucal.

Durante o tratamento odontológico curativo, foram realizados 52 exames (crianças novatas na escola); 50 reexames; destes, todos deram início ao tratamento odontológico, sendo que 98 concluíram o tratamento. Q uanto aos infantes que não se submeteram ao exame clínico, deveu-se ao fato de os pais ou responsáveis não terem procurado os serviços da odontologia para a concretização do mesmo. Também foi realizada a escovação supervisionada, com evidenciação de biofilme de todas as crianças, por seis sessões, nas quais se procurou inserir conceitos de hi gienização e cuidados bucais de forma lúdica no cotidiano das mesmas.

No exame ceo-d, realizado para obtenção da representação numérica dosíndices de prevalência de cárie dental, ressairam os seguintes resultados:

. 1o período - 0,47;

. 20 período - 1,81;

. 3o período - 1,47; e

. 40 período - 2,82.

0 acompanhamento nutricional foi desenvolvido em três etapas, sendo:

1 à etapa - coleta de medidas antropométricas. Foram coletados peso e altura de todos os infantes. Para a avaliação, foram utilizados os índices peso para idade, altura para idade e peso para altura. Os que apresentaram desvio no estado nutricional (desnutrição, baixo peso, sobrepeso e obesidade) tiveram os pais ou responsáveis convidados a comparecerem na unidade do SESC para realização do acompanhamento dietoterápico.

Com o intento de realizar um acompanhamento mais expressivo, foram realizadas duas avaliações nutricionais. A primeira coleta de dados foi feita no mês de junho, analisando-se 119 crianças. A segunda foi realizada no mês de outubro e o número de infantes analisados foi de 117.

2a etapa: exame. 0 exame consistiu na avaliação nutricional pelo peso e altura, classificação do estado nutricional através da definição do percentil, anamnese alimentar para obtenção de informações sobre a história de saúde e hábitos alimentares do infante, determinação da conduta dietoterápica por meio de orientações aos pais e/ou responsáveis ou por fornecimento de um esquema alimentar para controle ou ganho de peso, com agendamento de retorno para acompanhamento periódico do infante. 0 número de exames realizados durante ano letivo foi de dezesseis.

3a etapa: tratamento. 0 tratamento consistiu da revisão das orientações nutricionais e cumprimento do esquema alimentar fornecido, revisão da anamnese alimentar e avaliação da adesão do infantee responsável ao tratamento proposto através da verificação da redução ou ganho de peso, que foi acompanhado por pesagem durante as consultas e alterações nos hábitos alimentares dos mesmos. A periodicidade do tratamento foi de acordo com a evolução do quadro em questão, totalizando dezesseis tratamentos.

Além do acompanhamento dietoterápico, foram desenvolvidas atividades para orientação aos infantes, pais e/ou responsáveis sobre a importância de uma alimentação saudável, formação de hábitos alimentares e estilo de vida benéfico para a promoção e/ou manutenção da saúde, as quais se deram por meio de uma palestra sobre alimentação saudável e durante dois plantões pedagógicos.

Também foi realizado um monitoramento, através do acompanhamento da distribuição dos lanches oferecidos pela educação infantil, buscando atender as exigências nutricionais e da clientela.

Fazia parte da proposta do projeto o acompanhamento social durante todo o seu processo de desenvolvimento; porém, não foi possível concretizá-lo, pois o serviço social ficou sem o profissional durante alguns meses. Tal fato gerou a realização de apenas três encontros com o grupo de pais, nos quais foram abordados os temas: limites da Educação, agressividade e sexualidade.

\section{Entrevistas}

Resultados

Dos 119 pais e/ou responsáveis pelos infantes, 79 concordaram em participar da entrevista, sendo que alguns optaram por não responder todas as perguntas. Os dados obtidos a partir de tais entrevistas estão expostos nas tabelas 1 a 5 . 
A pós a análise do ponto de vista dos pais e/ou responsáveis pelos infantes envolvidos no projeto, fez-se também necessário enfocar a opinião dos responsáveis pela execução do mesmo.

Tabela 1. Distribuição por número e porcentagem dos casos pesquisados, segundo o grau de satisfação com relação às orientações recebidas quanto à forma de execução do projeto.

\begin{tabular}{lcr}
\hline Orientações recebidas & $\mathrm{n}$ & \multicolumn{1}{c}{$\%$} \\
\hline Sim & 58 & $74,36 \%$ \\
Não & 01 & $1,28 \%$ \\
Razoável & 19 & $24,36 \%$ \\
Total & 78 & $100,00 \%$ \\
\hline
\end{tabular}

Fonte: SESC do M unicípio deAnápolis (GO).
A partir da análise preliminar das entrevistas, foram obtidos os seguintes resultados:

- Necessidades das crianças em seu contexto social: $47,36 \%$ dos entrevistados disseram que a principal maneira de reconhecer as necessidades das crianças é através da observação da situação financeira da mesma, em contrapartida a 31,57\% que relataram obter esta informação através da associação de fatores diversos como o comportamento do aluno em sala de aula, análise da ficha preenchida durante a matrícula, através de rodas de conversas, brincadeiras, entre outros: Acredito que podem ser várias, dependendo do contexto social que a criança está inserida, tais como através de conversas com a própria criança e família; conhecendo sua história de vida; atividades que possam detectar possíveis necessi dades; a própria observação em brincadeiras, jogos e seu cotidiano.

Tabela 2. Distribuição por número e porcentagem dos casos pesquisados, segundo opinião com relação ao acompanhamento médico, odontológico, nutricional e pedagógico dispensado ao infante durante a execução do projeto.

\begin{tabular}{|c|c|c|c|c|c|c|c|c|}
\hline \multirow{2}{*}{ Acompanhamento } & \multicolumn{2}{|r|}{ M édico } & \multicolumn{2}{|c|}{ Odontológico } & \multicolumn{2}{|c|}{ Nutricional } & \multicolumn{2}{|c|}{ Pedagógico } \\
\hline & $\mathrm{n}$ & $\%$ & $\mathrm{n}$ & $\%$ & $\mathrm{n}$ & $\%$ & $n$ & $\%$ \\
\hline Ótimo & 18 & $23,68 \%$ & 28 & $35,44 \%$ & 19 & $25,33 \%$ & 34 & $44,15 \%$ \\
\hline Muito bom & 22 & $28,95 \%$ & 26 & $32,91 \%$ & 29 & $38,67 \%$ & 26 & $33,77 \%$ \\
\hline Bom & 33 & $43,42 \%$ & 22 & $27,85 \%$ & 24 & $32,00 \%$ & 17 & $22,08 \%$ \\
\hline Ruim & 03 & $3,95 \%$ & 02 & $2,53 \%$ & 02 & $2,67 \%$ & 00 & $0,00 \%$ \\
\hline Muito ruim & 00 & $0,00 \%$ & 01 & $1,27 \%$ & 01 & $1,33 \%$ & 00 & $0,00 \%$ \\
\hline Total & 76 & $100,00 \%$ & 79 & $100,00 \%$ & 75 & $100,00 \%$ & 77 & $100,00 \%$ \\
\hline
\end{tabular}

Fonte: SESC do M unicípio de Anápolis (GO).

Tabela 3. Distribuição por número e porcentagem dos casos pesquisados, de acordo com a participação nos encontros do grupo de pais e opinião com relação à relevância e formas de abordagens para os temas escolhidos para as palestras.

\begin{tabular}{lcr}
\hline Encontro grupo de pais & $\mathrm{n}$ & \multicolumn{1}{c}{$\%$} \\
\hline Sim & 57 & $73,08 \%$ \\
Não & 21 & $26,92 \%$ \\
Total & 78 & $100,00 \%$ \\
Pal estras & & \\
Ótimo & 33 & $50,77 \%$ \\
Muito bom & 20 & $30,77 \%$ \\
Bom & 12 & $18,46 \%$ \\
Ruim & 00 & $0,00 \%$ \\
Muito ruim & 00 & $0,00 \%$ \\
Total & 65 & $100,00 \%$
\end{tabular}

Fonte: SESC do M unicípio de Anápolis (GO).
Tabela 4. Distribuição por número e porcentagem dos casos pesquisados, segundo a aquisição de novos conhecimentos com relação à saúde da família através do projeto e aquisição de novos hábitos e/ou condutas a partir das informações obtidas por meio deste.

\begin{tabular}{lcr}
\hline \multicolumn{1}{c}{ Novos conhecimentos } & $\mathrm{n}$ & \multicolumn{1}{c}{$\%$} \\
\hline Sim & 61 & $82,43 \%$ \\
Não & 13 & $17,57 \%$ \\
Total & 74 & $100,00 \%$ \\
N ovos hábitos e/ou condutas & & \\
Sim & 51 & $66,23 \%$ \\
Não & 09 & $11,69 \%$ \\
Talvez & 17 & $22,08 \%$ \\
Total & 77 & $100,00 \%$ \\
\hline
\end{tabular}

Fonte: SESC do M unicípio de Anápolis (GO). 
Tabela 5. Distribuição por número e porcentagem dos casos pesquisados, com relação à nota atribuída ao projeto.

\begin{tabular}{lcc}
\hline Nota atribuída & $\mathrm{n}$ & $\%$ \\
\hline 01 & 00 & $0,00 \%$ \\
02 & 00 & $0,00 \%$ \\
03 & 01 & $1,27 \%$ \\
04 & 00 & $0,00 \%$ \\
05 & 02 & $2,53 \%$ \\
06 & 04 & $5,06 \%$ \\
07 & 09 & $11,39 \%$ \\
08 & 25 & $31,65 \%$ \\
09 & 23 & $29,11 \%$ \\
10 & 15 & $19,99 \%$ \\
Total & 79 & $100,00 \%$
\end{tabular}

Fonte: SESC do M unicípio de Anápolis (GO).

. Nota de envolvimento no projeto: a maioria atribuiu notas 9 e 10 para o seu envolvimento, dez relatos (52,63\%): N ove. Pois atuo de forma contínua, visando contribuir de forma significativa para a melhoria da qualidade de vida dos alunos e suas famílias a partir do fortalecimento de hábitos saudáveis em todos os aspectos que abrangem o projeto (médico, odontológico, nutricional e social).

- Treinamento e /ou reciclagem: $63,16 \%$ responderam ter participado de treinamentos e/ou reciclagens voltados para o projeto, além de relatarem a importância destas para um melhor desenvolvimento de suas ações juntos aos infantes e seu responsáveis: Sim. Há al guns anos venho participando de palestras e treinamentos em todos os aspectos queabrangem o projeto. Considero-os degrandevalia por nos proporcionar cada vez melhores condições de atuar junto aos nossos al unos ena orientação aos pais.

M as, apesar de participarem, alguns relatam que as capacitações não foram suficientes: Sim. Participei de algumas palestras, mas não são suficientes.

- Qualidade e abrangência dos serviços prestados: $63,16 \%$ relataram que o projeto é de grande relevância: A qualidade do projeto sem dúvida é de imensa relevância para a construção do conhecimento, pois estamos trabalhando com a educação infantil e nessa fase as crianças estão formando suas concepções.

Mas, apesar destes, muitos se contrapuseram com algumas ressalvas, dentre elas o desinteresse por parte de alguns pais: Com o seu desenvolvimento, está contribuindo para a melhoria da qualidade de vida dos alunos e de suas famílias, reforçando hábitos nos aspectos médicos, odontológicos, nu- tricional e social. Percebo que falta um pouco de interesse dos pais na participação do projeto.

- Encontro do grupo de pais: os executores do projeto em sua grande maioria $(73,68 \%)$ afirmam ser de grande importância os encontros dos grupos de pais e os mesmos expõem as dificuldades em conseguir atingir um maior número de participantes: 0 trabalho proposto éde excelentequalidade com profissionais capacitados, porém deveríamos propor outras formas de estar buscando um maior número de participantes. Os encontros são assuntos super interessantes que ajudam pais e professores a lidarem melhor com certos comportamentos e outros assuntos com nossos alunos.

- Mudanças de hábitos e/ou comportamentos: apenas um participantenão soube responder a essa indagação. Os demais $(94,74 \%)$ relataram que em maior ou menor grau notam mudanças de hábitos nos infantes: Sim. Há várias crianças que mudaram os hábitos alimentares, juntamente com a avaliação nutricional. A escovação e os hábitos de higiene oral também melhoraram muito, pois muitos pais foram orientados em acompanhar os filhos nos hábitos de higiene.

Sim. As crianças se tornam mais responsáveis quanto aos seus hábitos alimentares, hi giene bucal e saúde. Os pais ou familiares demonstram [aqueles que participam] interessados e buscam estar aplicando o que aprenderam na convivência dos seus filhos e nos procuram em busca dos atendimentos quando necessário.

\section{Discussõeseconsiderações finais}

Segundo Duhl ${ }^{9}$, avaliar é gerar conhecimento para sustentar eaprimorar processos. E a constante avaliação do processo, à luz de todos os envolvidos, é uma condição imprescindível para o sucesso do mesmo eisto requer que se engaje o maior número de participantes envolvidos (e não apenas pesquisadores) num processo abrangente de reflexão sobre a natureza da organização social e sobre os determinantes de saúde. Essa implementação de um processo de avaliação participativa pode favorecer a aglutinação crítica de atores sociais. A questão, então, éfazer do processo avaliativo não um exercício meramente científico, que busque possibilidades de se replicar experiências bem-sucedidas ou descartar aquel as mal-sucedidas com a singel a constatação do que é ou não é "efetivo"; mas também procurar se detectar, principalmente, por que tal projeto é efetivo ou por que não é "efetivo".

Conclui-se, então, quedesenvolver culturas avaliativas nos participantes - que possam favorecer 0 
exercício crítico para detectar especificidadesepotencializar mudanças de rumo, quando estas forem necessárias - éo eixo central para o constante aprimoramento. Em outras palavras, avaliar para aprender, agir e mudar. Pautada por essa máxima, por meio do estudo dos dados obtidos através da assistência prestada pelas diversas áreas afins ao Projeto AM ONS, assim como através das entrevistas equestionários, foi que se chegou a uma análise qualitativa quanto à atuação e diretrizes do programa.

$H$ á de se ressaltar queo papel fundamental das atividades pedagógicas no âmbito do projeto se fez sempre presente. Segundo La Salvia ${ }^{10}$, a escola promove a saúde na proporção em que consegue assegurar condições saudáveis tanto no espaço da sala de aula como dentro do espaço escolar. Condições saudáveis promovem um ambiente propício à aprendizagem, buscam estimular as relações entre as pessoas, promovem a participação e a criatividade do aluno e entendem quea auto-estima e a autonomia são aspectos fundamentais para a promoção da saúde.

Conforme observado, a escola também primou pelo favorecimento do intercâmbio entre família/ escola, pautando a educação como um processo dialógico, problematizador e inclusivo, que visa à construção da consciência crítica sobre o ser e 0 estar no mundo ${ }^{11}$. Proporcionando um ambiente solidário e propício ao aprendizado, mostrando-se engajada no desenvolvimento de hábitos saudáveis e na estimulação da criação de entornos favorecedores à saúde, na aprendizagem de comportamentos que permitam a proteção do meio ambiente, na conservação de recursos naturais e na implicação cada vez maior dos pais na rotina escolar dos infantes, bem como no Projeto AM ONS.

0 acompanhamento médico se deu por uma avaliação, cujo diagnóstico foi repassado aos pais dos infantes que possuíam alteração através de um informativo, mas não através do contato direto médico/pais. Já o esclarecimento sobreas enfermidades demaior incidência, assim como a importância do controle do cartão de vacina, foi realizado no dia da apresentação do projeto aos pais, por compreender ser este um espaço propício para o esclarecimento dos diversosquestionamentos apresentados.

0 acompanhamento odontológico foi realizado dentro do proposto no projeto, sendo que, após análise comparativa das condições de higiene bucal dos infantes no início e ao final do período de observação, os resultados se expressaram conforme apresentado no Gráfico 1.

Os dados nos possibilitam afirmar que houve uma significativa melhora na escovação dentária e consequenteremoção da placa bacteriana por parte dos infantes. Quanto às do primeiro período, como se tratam de crianças com aproximadamente três anos deidade, fica evidente a necessidade de um trabalho educativo mais efetivo juntos aos pais e/ou responsáveis, pois que são os principais responsáveis pela escovação dentária dessas crianças; cujos dados reafirmam os relatos das professoras quanto ao pequeno envolvimento dos pais no que tange à inserção de novos e salutares hábitos no cotidiano destas famílias.

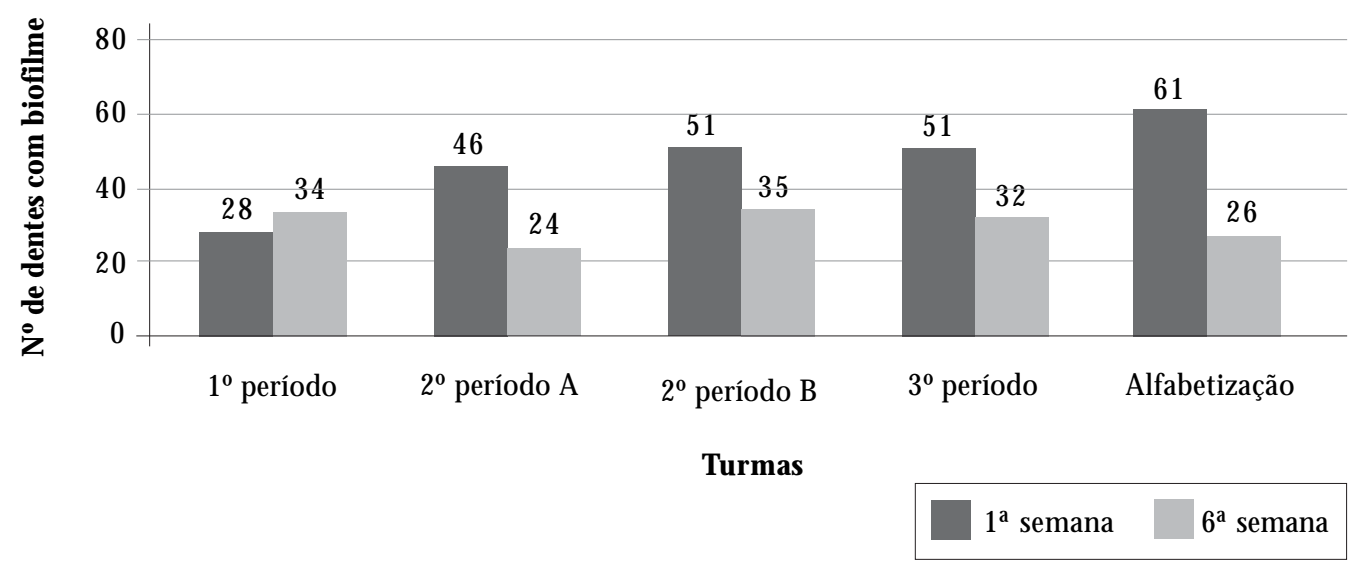

Gráfico 1. Índice de placa visível - 1a e 6a semana de acompanhamento. 
Os infantes com maior idade apresentaram uma maior incidência de problemas de ordem dentária, necessitando, para reverter este quadro, de mais ações em educação em saúde nos lares das famílias envolvidas no projeto, no afã de se tentar conseguir mudar este problema de ordem cultural e social brasileiro, trabalhando de maneira sistemática e gradual com os infantes para que os mesmos sejam multiplicadores junto aos seus familiares e suas comunidades.

Desta forma, ressalta-se a importância da manutenção e continuidade do referido programa, havendo necessidade da manutenção dos serviços de promoção em saúde bucal, implementando-se ações destinadas principalmente aos grupos de maior vulnerabilidade e/ou mais expostos aos fatores de risco.

O levantamento epidemiológico mostrou ser um instrumento importante para se diagnosticar as condições de saúde bucal desses infantes, possibilitando contribuir para o planejamento dos serviços de saúde a serem executados.

Procedemos ao cruzamento dos dados das avaliações das demais áreas, visando relacionar problemas deordem médica, nutricional e pedagógica com alterações das condições bucais dos mesmos, no qual observamos que os infantes com sobrepe so e obesidade possuem uma alta incidência $(42,86 \%)$ dealterações das condições bucais. 0 que nos possi bilita afirmar que a al ta ingestão de sacarose e carboidratos, assim como ingestão de alimentos fora dos horários das principais refeições, sem posterior escovação dos dentes, propicia ao acúmulo de biofilme e consequente alterações nas estruturas dentárias.

0 acompanhamento nutricional se deu deforma ampla e foi além das proposições do projeto, com a realização de uma segunda pesagem dos infantes ao final do ano letivo, contribuindo para a realização de uma análise comparativa com a primeira, realizada no início do ano letivo.

De acordo com os resultados, observa-se uma melhora do quadro geral dos infantes com desvios nutricionais. Dentreosalunos que se encontravam com baixo peso, três (50\%) procuraram acompanhamento nutricional e todos eles saíram do estado de vigilância e passaram para eutrofia. Dos desnutridos, também três $(42,8 \%)$ tiveram acompanhamento e dois passaram para baixo peso, permanecendo apenas um com o mesmo diagnóstico. Quanto ao sobrepeso, apenas cinco $(23,8 \%)$ alunos procuraram atendimento nutricional. Destes, três saíram da faixa de excesso de peso ficando eutróficos, um permaneceu com sobrepeso eum evolui para obesidade. I mportante ressaltar quea mes- ma não deu prosseguimento ao tratamento nutricional. Dos alunos com obesidade, apenas um (50\%) procurou atendimento e mesmo em acompanhamento manteve-seobeso. Posteriormente, foi detectado neste 0 quadro de hipotiroidismo, que justificou o diagnóstico nutricional.

M ostra-se como uma característica importante do projeto o uso das consultas dietoterápicas para os infantes com desvios nutricionais. Em princípio, tal característica afigura-se positiva à medida que revela a capacidade do projeto em atrair para si a parcela da população mais necessitada de orientação, ou seja, os infantes que já possuem alterações dos estados nutricionais. Entretanto, a pequena adesão por parte dos pais e/ou responsáveis mostra-se como um dos grandes entraves a este benefício efetivo conferido aos infantes com alterações nutricionais.

$N$ a medida em quetodos recebem o lancheconfeccionado na própria escola, sendo o mesmo preparado a partir de cardápios formulados pelo serviço de nutrição da instituição e acompanhado 0 preparo por uma estagiária do referido serviço, pôde-se evidenciar que esses são adequadamente suplementados durante a referida refeição. Tal fato per si não garante necessariamente um efeito positivo sobre o estado nutricional dos infantes beneficiados, uma vez que não se está considerando 0 consumo de outros alimentos, nem o estado de saúde dos mesmos. Entretanto, a importância nutricional desse lanche para a faixa etária coberta pelo projeto ea vinculação aos controles periódicos de saúde tornam aquela hipótese muito provável.

U ma outra característica importante do programa refere-se à sua estreita vinculação com a assistência à saúde, condição que deve ser vista como extremamente favorável na medida em que leva em conta o sinergismo existente na infância entre déficits na aten ção psicossocial e os agravos à saúde. Tal reconhecimento, é interessante lembrar, nem sempre tem prevalecido nos programas de promoção da saúde desenvolvidos no país, sendo o exemplo mais recente desta situação os programas nacionais de promoção da saúde instituídos pelo governo federal, cuja operação prescindede relações com a promoção e a assistência à saúde, sendo executados de maneira estanque e fragmentada nas diversas áreas de saúde, e não de maneira holística como apresentado no Projeto AM ONS. Apesar da atuação da assistência social através da interação escola/família ser de fundamental importância, deficiências existiram em decorrência da falta do referido profissional na unidade de referência, por al guns meses durante 0 ano, apesar das buscas da instituição por profissionais que se adequassem ao perfil da mesma. 
Dois outros traços marcantes do projeto são seu direcionamento para a faixa etária de três a seis anos e para a atenção à família dos mesmos, buscando a maior cobertura possível com a utilização de diversas atividades em busca da integração projeto/escola/família.

0 direcionamento das ações sociais para as correlações socioeconômicas com os agravos nutricionais, médicosedesaúdebucal éevidentemente positivo, uma vez que diferentes estudos realizados no restante do país têm demonstrado maior vulnerabilidadenutricional edas condições da saúde bucal e geral dos estratos menos privilegiados da população.

As percepções acerca do projeto pel os entrevistados sinalizam para a satisfação dos mesmos de maneira global, já pelos executores, para a necessidade de os coordenadores apresentarem de maneira mais clara o projeto aos mesmos, realizando, por exemplo, reuniões para leitura e esclarecimentos dedúvidas, em busca de uma unicidade de pensamentos, posturase consequentemente, ações, por meio de uma melhor comunicação entre idealizadores, gestores, coordenadores e executores. Considerando, assim, a importância de cada um dos envolvidos, suas sugestões, frustrações e opiniões a despeito do projeto, fazendo-se necessário a observação do papel constitutivo e constituidor dosmesmosna esfera de desenvolvimento do projeto, como argumenta Vygotsky ${ }^{12}$ : [...] o momento de maior significado no curso do desenvolvimento intelectual, que dá origem às formas puramente humanas deinteligência prática eabstrata, acontece quando a fala e a atividade prática, então duas linhas completamente independentes de desenvolvimento, convergem ${ }^{12}$.

O u seja, a palavra transforma e redimensiona a ação humana, mostrando a importância fundamental da comunicação contínua e efetiva.

Diante dos dados obtidos por meio deste, é possível observar que muita energia e movimento têm sido gastos no desenvolvimento de indicado- res quantitativos; tais indicadores podem ser úteis como estabelecimento de produtividade e de definição de prioridades, mas podem criar falsas expectativas daquilo que poderia ser modificado, no curto e no médio prazos, se for levada em conta apenas a magnitude dos problemas considerados, sendo imprescindível um novo olhar na forma de perceber, bem como novas maneiras de entender $e$ de agir em busca da promoção da saúde dos infantes envolvidos, lembrando sempreque mudanças de hábitos requerem tempo para se desenvolver. Competências também necessitam de tempo para se desenvolver. Mudanças no seio das comunidades necessitam do apoio dos vários níveis de governo, do setor privado local e das corporações globais, sendo este projeto um eixo positivo na busca dessas mudanças.

Algumas considerações finais devem ser feitas sobre a validade geral do Projeto AM ONS e sobre a necessidadede avaliá-lo. É evidenteque a dimensão da problemática da promoção da saúde no país e a origem basicamente social da mesma descartam a possibilidade deque o problema seja passível de solução pela mera atuação da escola na vida desses infantes. Tal solução requer um amplo conjunto de mudanças na sociedade, as quais, por sua vez, dependem de transformações radicais na estrutura de distribuição das riquezas do país. Por outro lado, embora limitados, programas de promoção da saúde, voltados para infantes, quando bem conduzidos, têm o mérito de proporcionar benefícios imediatos à população mais necessitada. No caso de crianças pequenas, em que agravos à saúde acarretam prejuízos severos e por vezes irreversíveis, intervenções de curto prazo são inegavelmente necessárias eimpostergáveis. Para que o projeto seja bem conduzido, mister se faz, entretanto, que aspectos mínimos de sua cobertura e impacto sejam avaliados, para que se torne factível a unicidade de ações na busca de uma interação multidisciplinar e multiprofissional. 


\section{Colaboradores}

TBM Oliveira foi responsável pela concepção, delineamento, pesquisa, análise e interpretação dos dados do trabal ho e redação do texto.

LH Presoto foi responsável pela orientação na concepção inicial do trabalho.

\section{Agradecimentos}

Ao Serviço Social do Comércio (SESC) de Goiás por permitir a realização do estudo, em especial ao Dr. Giuglio Settimi Cysneiros (Diretor Regional), ao Sr. M ário Watanabe Tomio (Diretor de Orientação Social) e à Sra. Simone A parecida Pereira ( $\mathrm{Ge}$ rente do SESC Anápolis), aos técnicos responsáveis pela execução do Projeto AM ONS em Anápolis, à colaboração fundamental dos voluntários e a todos que possibilitaram a realização deste estudo.

\section{Referências}

1. Freire P. Educação como prática da liberdade. 29ạ ed. Rio de Janeiro: Paz e Terra; 1999.

2. Pereira IMTB, Penteado RZ, M arcelo CV. Promoção da saúde e educação em saúde: uma parceria saudável. 0 M undo da Saúde 2000; 24(1):39-44.

3. Oliveira DL. A 'nova' saúde pública e a promoção da saúde via educação: entre a tradição e a inovação. Rev Latino-am Enfermagem 2005; 13(3):423-431.

4. SESC GOIÁS. Programa de Trabalho 2005. Goiânia: SESC; 2004

5. Pinto VG. A odontologia no município: guia para organização de serviços e treinamento de profissionais em nível local. Porto Alegre: RGO; 1996.

6. M inayo MCS. 0 desafio do conhecimento: pesquisa qualitativa em saúde. 5a ed. São Paulo: Hucitec; Rio de Janeiro: Abrasco; 1998.

7. Becker H. M étodos de pesquisa em Ciências Sociais. $3^{a}$ ed. São Paulo: Hucitec; 1997.

8. M inayo MCS, Sanches O. Quantitative and qualitative methods: opposition or complementarity? Cad Saude Publica [serial on the Internet]. 1993 Sep [cited 2007 Nov 16];9(3):[about 12 p.]. Available from: http:// www.scielo.br/scielo.php?script=sci_arttext $\&$ pid $=$ S0102-311X $1993000300002 \&$ Ing=en $\&$ nrm=iso

9. Duhl L, Hancock T. Community self-evaluation: a guide to assessing healthy cities. Copenhagen: $\mathrm{H}$ ealthy Cities Papers/ FADL; 1999.

10. La Salvia M W. Representação de saúde e prática pedagógica: o cotidiano de uma escola por ciclos [dissertação]. Porto Alegre (RS): Faculdade de Educação, Universidade Federal do Rio Grande do Sul; 2001.

11. Aerts D, Alves GG, La Salvia MW, Abegg C. Promoção de saúde: a convergência entre as propostas da vigilância da saúde e da escola cidadã. Cad Saude Publica [periódico na Internet]. 2004 [acessado 2007 nov 16];20(4):[cerca de 18 p.]. Disponível em: http:// www.scielosp.org/scielo.php?script=sci_arttext\&pid $=$ S0102-311X2004000400017\&lng $=$ pt\&nrm $=$ iso

12. Vygotsky LS. M ind in Society: The Development of $\mathrm{Hi}-$ gher Psychological Processes. Cambridge, MA: Harvard University Press; 1978.

Artigo apresentado em 10/06/2007

Aprovado em 27/08/2007

Versão final apresentada em 15/09/2007 